\title{
Participatory Varietal Selection of Food Barley (Hordeum vulgare L.) Genotypes in Ethiopia
}

\author{
Workineh Mekasa Buli* \\ Ethiopian Institute of Agricultural Research Ambo Agricultural Research Center
}

*Corresponding Authors: Workineh Mekasa Buli, Ethiopian Institute of Agricultural Research Ambo Agricultural Research Center

\begin{abstract}
Eight food barley genotypes were evaluated in randomized complete block design with three replications under farmers' participatory selection scheme at four locations in western Shoa, Central Ethiopia during 2019 main cropping season. The objectives of this experiment were to select superior food barley varieties in the study area and to identify farmers' preference and selection criteria. Farmers set number of kernels per spike, tillers per plant and plumpness as selection criteria at maturity stage of the crop. The results of the combined analysis of variance indicated highly significant differences among genotypes for all traits tested at $1 \%$ probability level. The GXE interaction also showed highly significant differences for all characters at $1 \%$ probability. The highest mean grain yield was obtained from the genotype EH-1493 (3320 Kg ha-1) followed by HB-1307 (3307 Kg ha-1) and HB-1966 (3257 Kg ha-1) whereas the lowest from the variety Guta (1835 Kg ha-1). Farmers' evaluation of direct matrix ranking showed HB-1307 (score 32) and HB-1966 (score 27) were the most preferred genotypes and the local check (score 13) the least one. Therefore, the genotypes HB-1307 and HB-1966 were chosen for their performance in the experimental field and also acceptable from farmers' participatory evaluation. Thus, based on the results of this study and previous information from the evaluation of the varieties, the selected varieties need to be popularized, multiplied and distributed to farmers.
\end{abstract}

Keywords: participatory selection, malt barley, genotype by environment interaction

\section{INTRODUCTION}

Barley (Hordeum vulgare L.) is an annual cereal crop most widely grown over broad environmental conditions. It has persisted as a major cereal crop through many centuries and it is the world's fourth important cereal crop after wheat, rice and maize (FAO, 2005). In Ethiopia, barley ranks fifth after teff, maize, sorghum and wheat (CSA,2016/17) in area of production. Barley has a long history of cultivation in Ethiopia and its production is reported to have coincided with the beginning of the plow culture (Zemede, 2000). It is one of the most important crop with total area coverage of 959,273.36 hectares and total annual production of about 2.1 million tons in main season (CSA, 2016/17). Barely is the most dependable cereal and is cultivated on highly degraded mountain slopes better than other cereal crops in the highlands of Ethiopia under extreme marginal conditions of drought, frost and poor soil fertility (Ceccarelli et al.,1999).

Barley genotypes are different in grain yield potential as well as different yield related agronomic traits (Mariey et al.,2013) and (Ahmed et al., 2001) and hence participatory research, where breeders or researchers work collaboratively with farmers needs due attention.

Participatory research in general and participatory breeding and/or varietal selection is minimal on barley in Ethiopia. Nevertheless, in recent years there has been increasing interest toward participatory research, in general, and toward participatory plant breeding (PPB), in particular. Plant breeding as a whole is a complex process, only a small fraction of it takes place in farmers' fields; usually, most of the process takes place in one, or more often in a number of research stations, and all the decisions are made by the breeders and collaborating scientists (pathologist, entomologist, quality specialists, etc.).

Participatory research, in general, defined as that type of research in which users are involved in the design, and not merely in the final testing, of a new technology, is now seen by many as a way to 
address these problems. PPB, in particular, defined as that type of plant breeding in which farmers, as well as other partners, such as extension staff, seed producers, traders, and NGOs, participate in the development of a new variety, is expected to produce varieties which are targeted (focused on the right farmers), relevant (responding to real needs, concerns, and preferences), and appropriate (able to produce results that can be adopted) (Bellon, 2006).

It is worth mentioning that although farmer participation is often advocated on the basis of equity, there are sound scientific and practical reasons for farmer involvement to increase the efficiency and the effectiveness of a breeding program (Ceccarelli and Grando, 2002).

From a scientific viewpoint, the process is similar to a conventional breeding program with three main differences, namely (i) testing and selection take place on-farm rather than on-station, (ii) key decisions are made jointly by farmers and breeder, and (iii) the process can be independently implemented in a large number of locations.

Despite the economic importance of barley in attaining food security and market access, very little have been done in the study area to change the livelihood of barley producing farmers. This is mainly due to poor participation of farmers in the selection process and poor intervention of improved agricultural technologies.

It is crucial to evaluate barley genotypes in their agro-ecology using the participatory varietal selection (PVS) approach so as to provide choices of varieties to the farmers. PVS also helps to disseminate the adoption of released varieties over a scope of wide area; allow varietal selection in targeted areas at cost-effectiveness and also in less time as a consequence help seed production and scaling-up at community level.

Hence, it is found imperative to evaluate barley genotypes for their performance and farmers' preferences thereby enhancing barley production and productivity in the area. Farmers handle the first phases of seed multiplication of promising breeding material in village-based seed production systems. The varieties reach the release phase earlier than in conventional breeding, the release and seed multiplication concentrate on varieties known to be acceptable by farmers, biodiversity increases because different varieties are selected in different locations, the varieties fit the agronomic management that farmers are familiar with and can afford, and, therefore, the varieties can be beneficial to poor farmers (Cecarelli \& Grando, 2009).

Large amount of breeding material is discarded without knowing whether it could have been useful in the real conditions of farmers' fields and the one that selected is likely to perform well in environments similar to research stations and may not perform as well in the fields of the poorest farmers. It is argued that, crops grown in environments poorly represented by the research stations; often results in discarding useful breeding material (Ceccarelli et al., 1996).

Therefore, this study was conducted to evaluate and select the best performing food barley genotypes and to identify farmers' preference and selection criteria for the varieties in the study area.

\section{MATERIALS AND MeTHODS}

\subsection{Experimental Design and Procedures}

A total of eight food barley genotypes (EH-1493, HB-1966, Cross-41/98, HB-1307, Abdane, Guta, Adoshe, Local check) were used in the study. The experiments were laid in randomized complete block design (RCBD) with three replications from July to December 2019. During planting, the seeds were manually drilled at a rate of $100 \mathrm{~kg} / \mathrm{ha}$ into 2.5 meters long ten rows plot spaced $0.2 \mathrm{~m}$ apart. NPS and UREA fertilizers were applied at the time of planting both at rate of $100 \mathrm{~kg} / \mathrm{ha}$. Hand weeding was practiced as frequently as needed.

\subsection{Data Collection}

Data were collected on plant and plot basis for different agronomic traits. For data collection on plant basis, five plants were randomly taken from the eight middle rows of each plot excluding the two rows on both sides of each plot as borders and the mean value of those five plants was calculated and used as plot data for analysis, where for the on plot basis, the eight middle rows were considered and finally harvested for the plot data. Plant height $(\mathrm{cm})$, spike length $(\mathrm{cm})$ and number of kernels per 
spike were recorded on plant basis; whereas days to $50 \%$ heading, days to physiological maturity, grain yield $\left(\mathrm{kg} \mathrm{ha}^{-1}\right)$ and stand count $(\%)$ were recorded on plot basis.

\subsection{Statistical Analysis}

The data were analyzed using PROC GLM in SAS software version 9.00. Mean separation was carried out using $t$ test.

\subsection{Participatory Varietal Selection Procedures}

Farmers set and prioritized criteria for the participatory selection. The criteria for selection included spike length, number of tillers, number of kernels per spike, plumpness of the kernel and the like.

The genotypes were evaluated using farmers' selection criteria. A total of twenty farmers of both sexes (male $=13$, female $=7$ ) participated in the study. Farmers were allowed to set their own selection criteria and then both male and female participants prioritized and jointly agreed on preferred characters. All of them were tabulated in a matrix scoring table, and each selection criterion was compared with another in a pair wise fashion. The rank assignments were determined from the number of times each selection criterion was preferred by the group. A direct matrix table was prepared for the barley genotypes. Scores were given to each variety based on the selection criteria (5 $=$ very good, $4=$ good, $3=$ average, $2=$ poor, and $1=$ very poor). During direct matrix ranking farmers have given rating of importance (a relative weight) of a selection criterion ranked from 1 to 3 ( 3 = very important, $2=$ important and $1=$ less important) and rating of performance of a variety for each traits of interest (selection criteria) was given based on their level of importance on the basis of common agreement of evaluators'. The score of each variety was multiplied by the relative weight of a given character to get the final result and then added with the results of other characters to determine the total score of a given variety. Scoring and ranking were done on consensus, and differences were resolved by discussion as indicated by de Boef and Thijssen (2006).

\section{RESUlT AND DISCUSSION}

The results of the combined analysis of variance (ANOVA) showed highly significant $(\mathrm{P}<0.01)$ differences among the food barley varieties for all characters measured (Table 1).

Table1. Mean squares of ANOVA for food barley parameters measured in 2019 main cropping season

\begin{tabular}{lcccccc}
\hline \multicolumn{7}{c}{ Mean squares } \\
\hline S.V & DF & PlH & GFP & Stand & SL & YLD \\
\hline Loc & 3 & $514.59^{* *}$ & $1380.29^{* *}$ & $324.57^{* *}$ & $8.09^{* *}$ & $415775.87^{* *}$ \\
Gen & 7 & $825.52^{* *}$ & $78.95^{* *}$ & $310.47^{* *}$ & $9.18^{* *}$ & $679439.46^{* *}$ \\
Loc x gen & 21 & $95.45^{* *}$ & $35.47^{* *}$ & $130.11^{* *}$ & $0.72^{* *}$ & $208361.28^{* *}$ \\
Error & 0.19 & 4.31 & 0.52 & 0.01 & 39587.34 \\
\hline CV \% & 0.43 & 4.44 & 0.81 & 1.41 & 17.67 \\
\hline$*=$ significantly different at 5\% probability level, $* *=$ at 1\% probability level \\
PlH = plant height, GFP = grain filling period, Stand = stand percentage at maturity, SL = spike length, YLD \\
$=$ grain yield.
\end{tabular}

Mean values of tested genotypes for the characters studied in West Shoa are given in Table 2.

The grain filling period ranged from 42 days for the variety EH-1493 to 49 days for Guta and HB1307.

The mean plant height recorded was $100.9 \mathrm{~cm}$ with a range of 83 to $108.8 \mathrm{~cm}$. The shortest plant height was recorded for the variety Adoshe while the tallest plant height was recorded for the local check. The stand count of the varieties ranged from 79.6 for Guta to $95.3 \%$ for the variety Eh-1493. 
Table2. Mean Values of Growth, Yield and yield related Parameters of Food Barley Varieties in Western Shoa in 2019 main cropping season

Varieties Mean Values

\begin{tabular}{lccccc}
\hline & GFP & PH & Stand & SL & YLD \\
\hline EH-1493 & $42.6 \mathrm{D}$ & $104.0 \mathrm{D}$ & $95.3 \mathrm{~A}$ & $7.5 \mathrm{C}$ & $1328.3 \mathrm{~A}$ \\
HB-1966 & $47.5 \mathrm{BC}$ & $103.5 \mathrm{E}$ & $92.9 \mathrm{~B}$ & $6.8 \mathrm{~F}$ & $1303.1 \mathrm{~A}$ \\
Cross-41/98 & $43.7 \mathrm{D}$ & $107.0 \mathrm{~B}$ & $91.3 \mathrm{C}$ & $7.1 \mathrm{D}$ & $1255.7 \mathrm{~A}$ \\
HB-1307 & $49.4 \mathrm{~A}$ & $100.0 \mathrm{~F}$ & $93.3 \mathrm{~B}$ & $6.3 \mathrm{H}$ & $1323.6 \mathrm{~A}$ \\
Abdane & $46.3 \mathrm{C}$ & $105.5 \mathrm{C}$ & $86.2 \mathrm{E}$ & $7.0 \mathrm{E}$ & $1032.8 \mathrm{~B}$ \\
Guta & $49.6 \mathrm{~A}$ & $96.0 \mathrm{G}$ & $79.6 \mathrm{~F}$ & $6.6 \mathrm{G}$ & $734.0 \mathrm{C}$ \\
Adoshe & $46.3 \mathrm{C}$ & $83.0 \mathrm{H}$ & $88.8 \mathrm{D}$ & $7.6 \mathrm{~B}$ & $1215.8 \mathrm{~A}$ \\
Local & $48.5 \mathrm{AB}$ & $108.8 \mathrm{~A}$ & $86.3 \mathrm{E}$ & $9.1 \mathrm{~A}$ & $813.3 \mathrm{C}$ \\
Mean & 46.7 & 100.9 & 89.2 & 7.3 & 1125.8 \\
CV & 4.4 & 0.4 & 0.8 & 1.4 & 17.6 \\
\hline
\end{tabular}

GFP = Grain Filling Period, PH = Plant Height, Stand = Crop Stand percentage, SL $=$ Spike Length and YLD $=$ Grain Yield in $\mathrm{Kgha}^{-1}$

The mean spike length of the varieties recorded was 7.3 with a range of 6.3 to $9.1 \mathrm{~cm}$. The shortest spike was recorded for HB-1307 where the longest was recorded for the local check. The spike length being an important character in barley contributes highly for yield.

The grain yield of the varieties ranged from 1835 to $3320 \mathrm{Kgha}^{-1}$ with mean of $2814 \mathrm{Kgha}^{-1}$. The lowest grain yield was recorded for the variety Guta and the highest recorded for the variety EH- 1493 followed by HB-1307 and HB-1966.

\section{Farmers' evaluation of food barley genotypes:}

Selection criteria of farmers in the study area were based on a wide discussion and consensus and farmers set tillers per plant, kernels per spike and kernel plumpness as selection criteria during maturity stage of the crop. These selection criteria were used in varietal selection study conducted by Yetsedaw and colleagues (Yetsedaw et al., 2010). Direct matrix was made with the criteria in the columns and tested varieties in the rows (Table 3).

Table3. Direct Matrix ranking evaluation of food barley genotypes by group of farmers at West Shoa in 2019 main cropping season

Variety Selection Criteria

\begin{tabular}{lccccl} 
& NKS & TPP & Plumpness & Total & \multirow{2}{*}{ Rank } \\
\cline { 2 - 5 } \multicolumn{1}{c}{ Weight } & 3 & 3 & 2 & & \\
\hline EH-1493 & $9(3)$ & $6(2)$ & $4(2)$ & 19 & 6 \\
HB-1966 & $9(3)$ & $12(4)$ & $6(3)$ & 27 & 2 \\
Cross-41/98 & $9(3)$ & $6(2)$ & $6(3)$ & 21 & 4 \\
HB-1307 & $12(4)$ & $12(4)$ & $8(4)$ & 32 & 1 \\
Abdane & $6(2)$ & $9(3)$ & $6(3)$ & 21 & 4 \\
Guta & $6(2)$ & $6(2)$ & $4(2)$ & 16 & 7
\end{tabular}




\begin{tabular}{lccccc}
\hline Adoshe & $9(3)$ & $9(3)$ & $6(3)$ & 24 & 3 \\
Local & $6(2)$ & $3(1)$ & $4(2)$ & 13 & 8 \\
\hline
\end{tabular}

Farmers' evaluation of direct matrix ranking showed HB-1307 (score 32) and HB-1966 (score 27) were the most preferred genotypes and the local check (score 13) the least one. Thus the varieties HB1307 and HB-1966 were chosen to be popularized and widely distributed for production.

PVS was done in the study area as most of the tested genotypes were new and/or not disseminated very well in the study area.

\section{REFERENCES}

[1] Ahmed, I. A., El-Hag, A. A., Amer, K. A., El-Moselhy, M. A., \& Said, M. A. (2001). Evaluation of some

[2] barley genotypes for salt tolerance. National Coordination Meeting, Egypt, ARC, Cairo, Sept., 2-4.

[3] Bellon, M. R. (2006) Crop Research to Benefit Poor Farmers in Marginal Areas of the

[4] Developing World: A Review of Technical Challenges and Tools. CAB Reviews:

[5] Perspectives in Agriculture, Veterinary Science, Nutrition and Natural Resources. Online

[6] ISSN 1749-8848.

[7] Ceccarelli, SS. Grando, V. Shevostove, Vivar, H Yahyaoui, A, El-Bhoussini, M.and Baun M., (1999). ICARDA Strategy for global barley improvement. RACHIS .18:3-12

[8] Ceccarelli S, Grando S, Booth RH., (1996). International breeding programmes and resource-poor farmers: crop improvement in difficult environments. pp. 99-116, In: Participatory plant breeding. Eyzaguirre P. and Iwanaga M. (Eds) Proceeding of a workshop on participatory plant breeding, 26-29 July 1995, Wageningen, The Netherlands. IPGRI, Italy.

[9] Ceccarelli, S. and Grando, S. (2002) Plant Breeding with Farmers Requires Testing the Assumptions of Conventional Plant Breeding: Lessons from the ICARDA Barley Program. In: D. A. Cleveland David and D. Soleri (Eds.), Farmers, Scientists and Plant Breeding: Integrating Knowledge and Practice.Wallingford, Oxon, UK: CAB I Publishing International. pp. 297-332.

[10]CSA., (2016). Central Statistics Authority Report on Area and Production of Crops. Statistical Bulletin of Agricultural Sample Survey, Volume IV, No. 446, Addis Ababa, Ethiopia.

[11]De Boef WS, Thijssen MH (2006). Participatory tools working with crops, varieties and seeds. A guide for professionals applying participatory approaches in agro biodiversity management, plant breeding and seed sector development. Wageningen, Wageningen International. $29 \mathrm{p}$

[12]FAO., (2005). Food and Agriculture Organization of the United Nations. Estimates of world production and harvested area . Data from faostat.fao.org.

[13] Mariey S.A, Mohamed M.N, Khatab I.A, El-Banna A.N, Khalek A.F \& Al-Dinary M.E, (2013). Genetic Diversity Analysis of Some Barley Genotypes for Salt Tolerance Using SSR Markers. Journal of Agricultural Science; Vol. 5, No. 7; 2013

[14] Yetsedaw A, Tadesse D, Wondimu B (2010). Participatory Evaluation of malt barley (Hordiumvulgare L.)Genotypes for yield and other agronomic traits at North- west Ethipoia. Wudpecker J. Agric. Res. 2(8):218-222.

[15]Zemede Asfaw, 2000. The Barley of Ethiopia.pp 77- 108. In: Stephen B. Brush(ed). Genes in the Field: On farm Conservation of Crop Diversity. IDRC/IPGRI.

Citation: Workineh Mekasa Buli " Participatory Varietal Selection of Food Barley (Hordeum vulgare L.) Genotypes in Ethiopia." International Journal of Research Studies in Agricultural Sciences (IJRSAS), 2021; 7(1), pp. 32-36, https://doi.org/10.20431/2454-6224.0701004

Copyright: () 2021 Authors. This is an open-access article distributed under the terms of the Creative Commons Attribution License, which permits unrestricted use, distribution, and reproduction in any medium, provided the original author and source are credited. 